\author{
Liridon Dalipi, asistent \\ University of Gjilan "Kadri Zeka", Kosovo
}

\title{
INDEPENDENCE OF INDEPENDENT INSTITUTIONS: THE CASE OF INDEPENDENT MEDIA COMMISSION (IMC) IN KOSOVO
}

\author{
Udk: 327 : 343 (497.6) \\ Profesional paper \\ Primljeno: 10. 5. 2016.
}

This paper addresses the issue of independent institutions in Kosovo that are constitutional category, their operation and role within the state, problems and challenges that arise especially in those areas that the issue of regulation is very sensitive. The key focus in this study is IMC.

This paper contains analysis of political influence on financing and appointment in decision making bodies. Furthermore, it includes analysis of the political independence from industry. These issues will be addressed according to the guidelines and recommendations of the European Union compared with domestic legislation and various European practices. This study has been done using secondary data, and it concludes that Independent Institutions in Kosovo are not immune from the political and industry influences, and it provides some recommendations on how to avoid such influences.

Key words: Influences, Independence, IMC, financing, political, industry.

\section{INTRODUCTION}

Independent institutions play a very important role in a contemporary society. Their independence in relation to state bodies and political parties essentially reflects the democratic culture, development concept, intellect, social direction, and expectations of citizens.

The more powerful and independent are the independent institutions; their decisions will be so beneficial for societies where they operate. Therefore, it is vital that independent institutions function on the basis of the principle of balance and control, with full responsibility and accountability to the public interest. Societies that have emerged out of transition, wars, or those that have embraced the liberal political concept of decision making, have immensely benefited from the independent functioning of these institutions. Furthermore, these institutions have contributed greatly to the country's democratization, economic development, freedom of expression, social equality, and in the process of European and EuroAtlantic integration. 
The Republic of Kosovo, along with the state-building process has worked regularly in the legal infrastructure and funding in order to strengthen independent institutions gradually and function in harmony with the directives of the European Union. Despite the great progress that has been exceptionally made in recent years, independent institutions in reality still are not immune to political and industrial interferences.

The purpose of this research is to conduct an objective evaluation of the functioning of independent institutions in Kosovo, with particular emphasis on the Independent Media Commission (IMC), due to the role, its function and importance in direct relation with printed and electronic media. And indirect contribution of this institution in all areas and fields of Kosovo's society.

\section{LITERATURE REVIEW}

\subsection{Influences in the Independent Institutions}

Separation and balance of powers, which was previously just a theoretic formulation, raised early in a general form of John Locke and fully elaborated and argued by Montesquieu, almost a century later, it still has influence in the state organization and operation of political institutions ${ }^{1}$.

The reason why most institutions have been created in the mid-90s, it may be that in most European countries, the political system has changed. We have gone through the processes of privatization and liberalization, and in the same time there has been a loss of trust in the institutions ${ }^{2}$.

Now, the independent institutions are responsible for the exercise of their activity, as guaranteed by the constitution and other legal acts. They perform activities independently on a specific area that is independent from other branches of government. Besides the autonomy in carrying out their activities, there is also the control mechanism, which aim is to prevent the abuse of power. In the Republic of Kosovo institutions have been created based on the principle of balance and control powers. The Constitution of the Republic of Kosovo in its article 4, defines separation of powers ${ }^{3}$.

1 Omari, L. Ndarja e Pushteteve dhe Pavarsia e Institucioneve Kushtetuese, Botimi Elena Gjika, Tiranë, 2011, page 3 .

2 Gilardi, F. Published by Edëard Elgar Publishing Limited Glensanda House Montpellier Parade Cheltenham Glos GL50 1UA UK 2008, page 4.

3 The Constitutional of the Republic of Kosovo, 15 June 2008, article 4 
As a point of study in this research will be the Independent Media Commission in Kosovo (IMC), which is an independent body and its powers are defined by Article 141 of the state top act on, in constitution ${ }^{4}$, this institution is responsible for the regulation, management and supervision of the broadcasting frequency spectrum.

Besides the Constitution of the Republic of Kosovo, the powers of the IMC are defined by the Law on IMC, among other things, the law stipulates that IMC regulates the rights, obligations and responsibilities of natural and legal persons who provide media services audio and audiovisual ${ }^{5}$, licenses public and private broadcasters, giving entities authorized the right to use frequencies in the frequency spectrum of the transmission, and licenses all audiovisual media services, and under the terms of the license, IMC requires those who obtain to respect the law and regulations issued by IMC.

Viewed from the perspective of a number of competencies, necessarily doubts are raised that where they are coming from members of the decision maker? Who appoints them? Or can they be independent from the influences of external forces to perform their function properly?, and for all issues and dilemmas raised the mind goes to the legal basis which determines the appointment manner, that what criteria the law of the IMC has defined.

But in this paper except the law, we have referred to the recommendations of the Committee of Ministers to member states on the independence and regulatory functions ${ }^{6}$. Among other where the legislative framework specifies that Member States should ensure the establishment and unimpeded functioning of regulatory authorities for the broadcasting sector by devising an appropriate legal framework. The rules and procedures governing or affecting the functioning of regulatory authorities should clearly affirm and protect their independence.

Duties and powers of the regulatory authorities for the broadcasting sector, and the ways making them accountable, the procedures for appointment of their members and the means of their funding should be clearly defined by law, and without doubt these are two elements that significant impact the regulatory independence, because if we have political appointment or is funding that goes through government control, obviously we do not have independence, so we need a clear definition in order to protect the independence of institutions of any intervention, especially by political forces or economic interests.

4 The Constitutional of the Republic of Kosovo, 15 June 2008, article 141, page 58.

5 Law on Independent Media Commission, N0. 04/L-44, 2 March 2012, article 3.

6 Recommendation Rec (2000)23 of the Committee of Ministers to member states on the independence and functions of regulatory authorities for the broadcasting sector (Adopted by the Committee of Ministers on 20 December 2000 at the $735^{\text {th }}$ meeting of the Ministers' Deputies). 
To this end, the recommendation of the Committee of Ministers foresees that should be set specific rules regarding incompatibility, as defined in order to avoid that regulatory authorities are under the influence of political power, members of regulatory authorities not to exercise functions or hold interests in other companies or organizations in the media or related sectors, which could lead to a conflict of interest in connection with membership of the regulatory authority. Furthermore, rules should guarantee that the members of these authorities are appointed in a democratic and transparent way, not to come from interest groups, not to be close to them or not take instructions from any external body. But this is not enough that only a provision in the law superficially to note that these actions are not permissible.

Where we should focus on more is the way of appointing candidates to decisionmaking body for the independent institutions, the right to nominate, and the barriers to become a candidate. Also very important is the composition of the committees dealing with interviewing and selection of candidates (usually done by deputies and it all is dictated by party recommendation), then see how to achieve the objective that an institution be independent. Legal regulations must clearly specify the actions to be taken to achieve the goal.

Based on our reality and what is required by IMC law, certainly we notice some shortcomings starting it that one of the criteria is that it does not allow IMC employees to be members of the decision-making, with this prohibition law lawmakers make a legal and practical error here, when we say so, we consider legal law of Kosovo civil servants which does not provide these prohibitions..

While the practice part is that the IMC staff throughout their careers are associated with the regulation of the media and, it is said that they are professional in this area, and to forbid them to obtain such positions is certainly is absurd in itself. Even more, it is another point of the law which stipulates that former employees of the IMC in two (2) years are after leaving IMC are strictly forbidden to be considered for positions in decision making body. This means that if a person want to advance in their professional career should be out of professional flows for two years and after this period, such candidates certainly will be have lack of relevant information and not very competent to run for decision-making body. The purpose of these two provisions are entirely without any analysis and are not based on any practice of independent institutions within the country, or even international practices. 


\section{METHODOLOGY}

In this research, qualitative methods will be used with the focus IMC, as an independent institution in Kosovo. Critical analysis will be adapted to derive a more efficient research. This research was developed based on secondary data, using existing literature, reports from various international academic journals, and existing laws. These data are derived from reliable sources, impartial and academic with a very high level of quality.

Data analysis used in this study is of the interpretive technique. The most common analysis of qualitative data is observer impression, a situation where the researcher observes and analyzes the data, interprets through the formation of an impression and reports the impression in the structured form and quantitative sometimes.

\section{ANALYSIS}

\subsection{Political Influences}

Also, with the law of the IMC is tried to avoid political interference in the process-of appointments making it impossible to be a member of the decisionmaking persons holding public positions, elected and appointed (the public officials) or persons who have been in these positions during the last two (2) years, members in the leadership positions of a political party or persons who have been in these positions during the two (2) years ${ }^{7}$. The lawmaker apparently even here have not well specified, since in practice many high ranking officials of political parties are presented who are not elected and are not part of the governing body, such as the advisers of head of political parties or political party spokespersons, and other similar cases, where these individuals are considered too close to political parties, while the law does not provide stops for them.

Continuous political interference are evident, it is mentioned in international reports $^{8}$, which states that the independence of media regulator has been challenged by political interference.

7 Law on Independent Media Commission, No. 04/L-44, 2 March 2012, article 12, page 9

8 European Commission, Kosovo Progress Report, 2014, page 51. 
Besides political interference, the other problematic is the impact of industry or interest groups that have the greatest impact and for this the law determines, but still does not clearly specify that persons who have a financial interest, directly or who currently work or who has worked in any broadcaster in the operation of telecommunications or broadcasting and in the IMC in the last two (2) years, cannot be nominated for the members of the decision-making body.

\subsection{Impacts from the financing}

It can rightly be concluded that these restrictions are more for illustration of the law, as oppose to achieve the certain effect, the reason is that if we refer to the law of the IMC, and stop first at ways of financing, we note that although the IMC by law collects the license fee $^{9}$, the same is unable to utilize for its services, which means the use of these be conform rules as stated in the law for the management of public finances, but as a way of financing IMC, allocated financial resources from state budget are foreseen.

The funding manner of independent institutions in general is not assessed practically, because there is not available a special funding structure. Part of the majority of these institutions is funded directly from the state budget of Kosovo, with the exception of a limited number that are allowed by law to collect the revenue from licensee's fees. For reason of not a good execution of payments, most institutions fail and face difficulty to collect revenue other than those that are separate from the central budget.The survey that is done by the OSCE on the financing of independent institutions shows that the low budget prevents them to perform their activities and functions due to insufficient budget. Separate budget lines from the central budget are too small in relation to the initial demands that these institutions consistently address ${ }^{10}$.

In current situation, to overcome financing barriers and in order for the independent institutions to exercise their power free of influences, the lawmakers should amend the laws and provide means of financing other than from state budget. All the income that derives from license fees, fines and penalties, membership fees directly should go into the institutions where it belongs. The state role should be only of supervision nature to ensure that payments are received and processed according to existing laws.

9 Law on Independent Media Commission, Nr. 04/L-44, 2 March 2012, article 3, page 5

10 OSCE (2012). The State of Independent Institutions in Kosovo. Organization for Security and Cooperation in Europe, mission in Kosovo. 


\subsection{Impacts from Industry}

The main point that foresees the recommendation of the Committee of Ministers is the impact of the industry, and if we stop just at this issue we see that here except for cases of conflict of interest in decision-making, we have to do with the impact of the industry power, which especially happens via media through various television stories based on news reporting while at the same time we can say that this is blackmail, and it occurs prior to taking a decision that potentially harms the interests of industry players.

The law does not have strict and clear restrictions, and it casually mention a few stops, and we can say that the essential elements of the impact of the industry are not addressed in the law of the IMC, except others does not stop to be part of the decision making body people who have their relatives in management positions in any company that their work is related to IMC, or other case sets limits only for last two years, which means that for a few years a regulator of the media can be guided by former journalist and former editor of a particular medium

\section{CONCLUSION}

We can clearly observe that the three key elements that an independent institution to be independent have not been adequately addressed by the legislation in force, and for this it can be concluded that independent institutions face problems of political and financial influence at all times. There have been different influences that have started with appointment method of decision making bodies, the way financing as well as other different influences from interest groups.

To this end, this has been argued international reports, such as Kosovo Progress Report of 2014, but not only, who among others stress that independent institutions are challenged by political interference and other interventions.

In order to avoid political and other interventions, it is necessary to think about:

- A reformation of the legal regulations that guarantee the functioning of these institutions;

- To have a special care at the means of financing (from the income generated by the services they perform or from state budget);

- The criteria that should be met for the candidates to become members of decision making body; 
- The composition of committees for interviewing and preparing the final list of candidates;

- A clear distinction of competences between the decision-making powers which are temporary and professional staff that is permanent, and to ensure that both will do their job independently.

\section{REFERENCES}

Omari, L. Ndarja e Pushteteve dhe Pavarsia e Institucioneve Kushtetuese, Botimi Elena Gjika, Tiranë, 2011.

Gilardi, F. Published by Edward Elgar Publishing Limited Glensanda House Montpellier Parade Cheltenham Glos GL50 1UA UK 2008.

The Constitution of the Republic of Kosovo, 15 June 2008.

Law on Independent Media Commission, N0. 04/L-44, 2 March 2012.

Recommendation Rec (2000) 23 of the Committee of Ministers to member states on the independence and functions of regulatory authorities for the broadcasting sector (Adopted by the Committee of Ministers on 20 December 2000 at the $735^{\text {th }}$ meeting of the Ministers' Deputies).

European Commission, Kosovo Progress Report, 2014.

OSCE (2012). The State of Independent Institutions in Kosovo. Organization for Security and Co-operation in Europe MISSION IN KOSOVO 